\title{
A Model of Ice Wedge Polygon Drainage in Changing Arctic Terrain
}

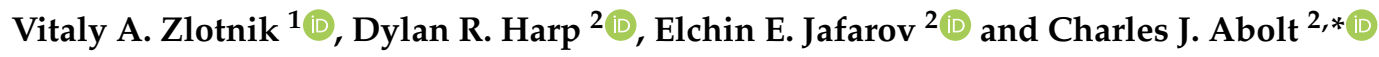 \\ 1 Department of Earth and Atmospheric Sciences, University of Nebraska-Lincoln, Lincoln, NE 68588, USA; \\ vzlotnik1@unl.edu \\ 2 Earth and Environmental Sciences Division, Los Alamos National Laboratory, Los Alamos, NM 87545, USA; \\ dharp@lanl.gov (D.R.H.); elchin@lanl.gov (E.E.J.) \\ * Correspondence: cabolt@lanl.gov
}

Received: 25 September 2020; Accepted: 25 November 2020; Published: 1 December 2020

check for updates

\begin{abstract}
As ice wedge degradation and the inundation of polygonal troughs become increasingly common processes across the Arctic, lateral export of water from polygonal soils may represent an important mechanism for the mobilization of dissolved organic carbon and other solutes. However, drainage from ice wedge polygons is poorly understood. We constructed a model which uses cross-sectional flow nets to define flow paths of meltwater through the active layer of an inundated low-centered polygon towards the trough. The model includes the effects of evaporation and simulates the depletion of ponded water in the polygon center during the thaw season. In most simulations, we discovered a strong hydrodynamic edge effect: only a small fraction of the polygon volume near the rim area is flushed by the drainage at relatively high velocities, suggesting that nearly all advective transport of solutes, heat, and soil particles is confined to this zone. Estimates of characteristic drainage times from the polygon center are consistent with published field observations.
\end{abstract}

Keywords: ice wedge; thermokarst; active layer; flow net

\section{Introduction}

Polygonal tundra landscapes have experienced rapid change in recent decades. Across the Arctic, an abrupt acceleration in ice wedge degradation has been observed since the second half of the twentieth century [1-3]. This melting results in a deepening of troughs at polygon boundaries, which often become inundated. The formation and expansion of flooded troughs, or thermokarst pools (hereafter referred to as trough pools, for short), has profound influence on tundra hydrology and ecological processes. For example, in polygonal terrain with poorly developed (undegraded) troughs, hydrologic simulations suggest that most fluxes of water into and out of the active layer are vertical, either in the form of precipitation or evapotranspiration [2]. After troughs deepen, however, observations indicate that water may drain laterally from the active layer of the polygon interior throughout the summer [4-8]. A common result of this drainage is the flushing of nutrients and other solutes from polygonal soils into trough pools, where they may fertilize plant growth [7]. This flushing may be especially effective at mobilizing dissolved organic carbon, because exposure to sunlight following the discharge of water from tundra soils commonly accelerates oxidation [9].

Given the importance of this transition to tundra hydrology and carbon cycling, a number of studies have begun to incorporate ice wedge degradation into land surface models [10-13]. However, to our knowledge, very little work offers insights into the dynamics of active layer drainage at the scale of individual polygons $(\sim 10 \mathrm{~m})$. Here, we present a three-dimensional axisymmetric transient model of the flow above and inside an inundated low-centered polygon surrounded by flooded troughs, resulting in a simple analytical solution. Within our model, all subsurface flow occurs within 
a seasonally thawed layer which, depending on the time within the thaw season, is equal to or less thick than the active layer, here defined as the portion of the subsurface which experiences phase change between ice and liquid water [14]. Typically, the thickness of this thawed layer follows a roughly asymptotic trajectory, increasing quickly at the start of the summer, then gradually stabilizing near the active layer thickness late in the season. Accordingly, we studied an idealized (cylindrical) low-centered polygon, with a seasonally thawed depth $L$, and a radial distance $R$ from the center point to the interior wall of the rims; the depth $L$ can either be treated as constant for simulations of short time duration, or changed dynamically, using numerical or analytical approaches. Our model includes the effects of the polygon geometry, anisotropy, and hydrologic interconnection between the polygon center and the trough, with consideration of evaporation.

Parameterized by published field data from polygonal soils, the model indicates that water movement in the active layer occurs predominantly at the periphery of the polygon center, while the interior conducts very little water. Hence, advective flushing of mass, solutes, and energy is confined primarily to a small region at the edge of the polygon.

\section{Conceptual Model}

We consider a three-dimensional axisymmetric transient model of the flow in an inundated, cylindrical, low-centered polygon in which a thermokarst pool had begun to develop, characterized by a thawed layer of depth $L$, and a distance $R$ from the center point of the polygon to the start of the rim (Figure 1). Pools of water exist both in the center and in the trough.

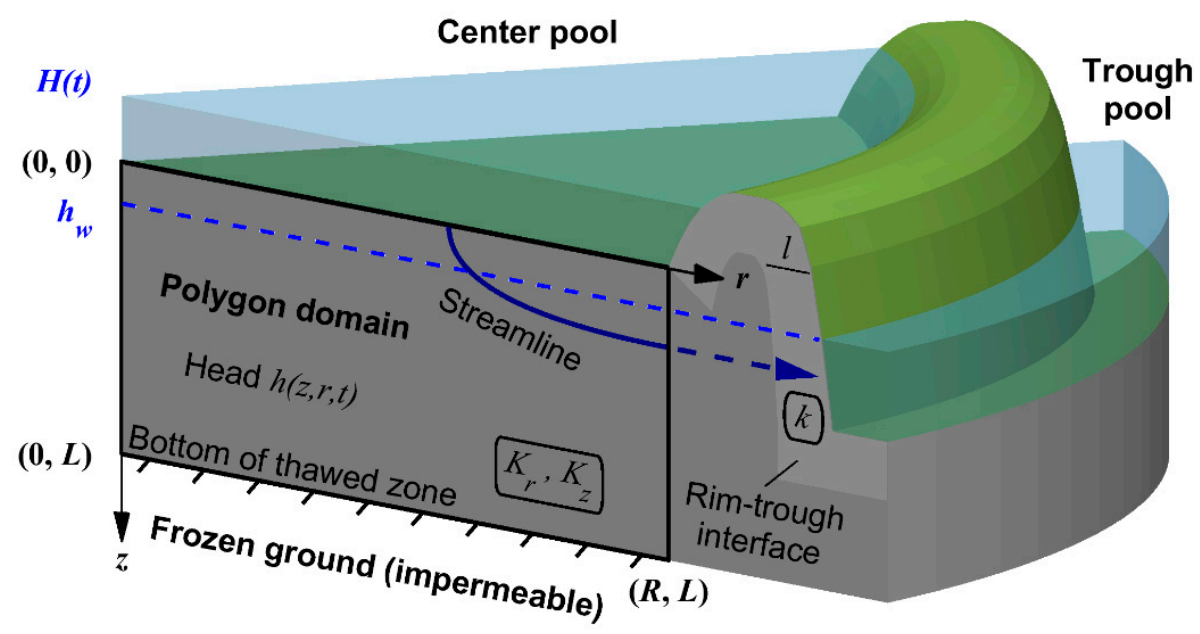

Figure 1. Schematic diagram of our three-dimensional axisymmetric analytical model of inundated low-centered polygon drainage. The diagram represents an idealized "pie wedge" section of a low-centered polygon, including pools in the center and trough.

In cylindrical coordinates $(r, z)$, the vertical $z$-axis is directed downward from the polygon surface while $r$ is the radial coordinate, which is zero at the polygon center. The datum for the hydraulic head is located at the base of the thawed layer. The pool has a uniform water level, $H(t)$, which reduces over time $t$, and is constrained from spilling by a rim separating the center from the trough (Figure 1). The water level in the trough with respect to the datum, $h_{w}$, is treated as constant.

Drainage of water through the active layer of the polygon center toward the trough pool is controlled by hydraulic resistance, which is dependent on horizontal and vertical hydraulic conductivity ( $K_{r}$ and $K_{z}$, respectively), polygon size, and the hydraulic exchange rate between the polygon and trough. The latter is defined by hydraulic resistance of the polygon-trough interface. This resistance is a function of interface thickness $l$ and hydraulic conductivity $k$. With finer sediments on the interface, one can assume $k<K_{r}$ (by a factor of about 2) [7]. In general, the thickness $l$ is less than the width of 
the rim, which may be in the order of several meters [15]. Thus, the flux across the polygon boundary $(r=R)$ at each elevation is defined by the difference between the head in the trough $\left(h_{w}\right)$ and the head in the polygon subsurface across from the trough at this elevation, $h(R, z, t)$. In general, the flux direction may vary.

The value $d=H(0)-h_{w}$ represents the initial head difference that drives the drainage. The drainage completion time, $t_{\text {drain }}$, is defined by the equation $H\left(t_{\text {drain }}\right)=L$.

Hydraulic head inside of the active layer, $h(r, z, t)$, responds rapidly to the center pool level at the surface $(H(t))$ due to the small vertical scale of the active layer. The polygon thickness $L(t)$ may vary from zero to a maximum value of $D$ and can be scaled as follows: $L(t)=D \cdot f(t)$, where $f(t)$ is a dimensionless function that varies from 0 to 1 by the end of the season. The thickness of the thawed layer can also be treated as constant for qualitative analyses or simulations of a short time duration.

\section{Methods}

\subsection{Problem Statement For Constant Thaw Depth}

In this case, $L=D$, a constant. Due to the small vertical scale of the polygon, soil compressibility effects on the flow of water through the active layer are neglected in the following flow equation:

$$
\frac{K_{r}}{r} \frac{\partial}{\partial r}\left(r \frac{\partial h}{\partial r}\right)+K_{z} \frac{\partial^{2} h}{\partial z^{2}}=0,0<r<R, 0<z<L
$$

The boundary condition at the z-axis indicates axial symmetry as follows:

$$
\frac{\partial h(0, z, t)}{\partial r}=0,0<z<L
$$

The boundary condition at the surface is defined by the pool level $H(t)$ :

$$
h(r, 0, t)=H(t), \quad 0<r<R
$$

Exchange of water across the polygon interior/trough interface (i.e., under the rim) can be described using a Robin boundary condition that relates flux to the difference in head at each elevation between the radial boundary and the trough, through the coefficient $\kappa$ :

$$
-K_{r} \frac{\partial h(R, z, t)}{\partial r}=\kappa\left[h(R, z, t)-h_{w}\right], \quad \kappa \approx k / l, \quad 0<z<L
$$

where $\kappa$ represents the conductance of the interface and rim. When the coefficient $\kappa=0$, the boundary is impermeable to drainage, while $\kappa \rightarrow \infty$ when water drains into the trough without added resistance, resulting in the boundary condition $h(R, z, t)=h_{w}$ (Figure 1).

The base of the thawed zone at $z=L$ is impermeable due to the frozen substrate:

$$
\frac{\partial h(r, L, t)}{\partial z}=0, \quad 0<r<R
$$

The variable level of water in the center pool is related to the drainage flux across the ground surface. Therefore, an additional equation of the mass balance of the water in the center pool is used, considering evaporative losses $E$ :

$$
\pi R^{2} \frac{d H}{d t}=-2 \pi K_{z} \int_{0}^{R} \frac{\partial h(r, 0, t)}{\partial z} r \cdot d r-\pi R^{2} E, \quad H(0)=H_{0}
$$




\subsection{Reduction to Dimensionless Steady-State Problem}

We introduce new dimensionless coordinates for space $\left(r^{*}, z^{*}\right)$ and time $\left(t^{*}\right)$ as follows:

$$
r^{*}=\frac{r}{L} \sqrt{\frac{K_{z}}{K_{r}}}, \quad z^{*}=\frac{z}{L}, \quad t^{*}=\frac{t}{t_{L}}
$$

and define functions for head $h^{*}\left(r^{*}, z^{*}\right)$ in the thawed zone and center pool depth $H^{*}\left(t^{*}\right)$ :

$$
h^{*}\left(r^{*}, z^{*}\right)=\frac{h(r, z, t)-h_{w}}{H(t)-h_{w}}, \quad H^{*}\left(t^{*}\right)=\frac{H(t)-h_{w}}{H_{0}-h_{w}}
$$

with dimensionless parameters:

$$
R^{*}=\frac{R}{L} \sqrt{\frac{K_{z}}{K_{r}}}, \quad B i^{*}=\frac{\kappa L}{\sqrt{K_{r} K_{z}}}, \quad Q^{*}=\int_{0}^{R^{*}} \frac{\partial h^{*}\left(r^{*}, 0\right)}{\partial z^{*}} r^{*} d r^{*}, \quad E^{*}=\frac{E \cdot t_{L}}{H_{0}-h_{w}}
$$

where the dimensional parameter $t_{L}$ below represents a characteristic drainage time of the model:

$$
t_{L}=\frac{R^{2}}{2 K_{r} L \cdot Q^{*}}
$$

These substitutions replace time-dependent $h(r, z, t)$ by the time-independent dimensionless function $h^{*}\left(r^{*}, z^{*}\right)$. The time dependence is embedded in $H^{*}\left(t^{*}\right)$ by Equation (8):

$$
h(r, z, t)=\left[H(t)-h_{w}\right] \cdot h^{*}\left(r^{*}, z^{*}\right)+h_{w}, \quad H(t)=\left(H_{0}-h_{w}\right) \cdot H^{*}\left(t^{*}\right)+h_{w}
$$

This transformation relies on the assumption that head inside the thawed zone responds rapidly to changes in the level of the center pool. The resulting boundary value problem for $h^{*}\left(r^{*}, z^{*}\right)$ is as follows:

$$
\begin{gathered}
\frac{1}{r^{*}} \frac{\partial}{\partial r^{*}}\left(r^{*} \frac{\partial h^{*}}{\partial r^{*}}\right)+\frac{\partial^{2} h^{*}}{\partial z^{* 2}}=0,0<r^{*}<R^{*}, 0<z^{*}<1 \\
\frac{\partial h^{*}\left(0, z^{*}\right)}{\partial r^{*}}=0, \quad 0<z^{*}<1 \\
-\frac{\partial h^{*}\left(R^{*}, z^{*}\right)}{\partial r^{*}}=B i \cdot h^{*}\left(R^{*}, z^{*}\right), \quad 0<z^{*}<1 \\
\frac{\partial h^{*}\left(r^{*}, L\right)}{\partial z^{*}}=0,0<r^{*}<R^{*}
\end{gathered}
$$

The dimensionless form of the water balance Equation (6) with initial conditions is:

$$
\frac{d H^{*}}{d t^{*}}=-H^{*}-E^{*}, \quad H^{*}(0)=1
$$

This equation explains drainage for the duration $0<t<t_{\text {drain }}$. 


\subsection{Solutions}

\subsubsection{Head $h^{*}\left(r^{*}, z^{*}\right)$}

The solution of the boundary value problem (12)-(16) for $h^{*}\left(r^{*}, z^{*}\right)$ can be found by the standard method of separation of variables. Details are presented in Appendix A.

$$
h^{*}\left(r^{*}, z^{*}\right)=2 \sum_{n=1}^{\infty} \frac{J_{0}\left(\lambda_{n} r^{*}\right)}{\lambda_{n} R^{*}\left[J_{0}\left(\lambda_{n} R^{*}\right)\left(\frac{\lambda_{n}}{B i}\right)+J_{1}\left(\lambda_{n} R^{*}\right)\right]} \frac{\cosh \left(\lambda_{n}(1-z)\right)}{\cosh \left(\lambda_{n}\right)}
$$

where $\lambda_{n}, n=1,2, \ldots$ are roots of the equation.

$$
\lambda_{n} J_{1}\left(\lambda_{n} R^{*}\right)=B i \cdot J_{0}\left(\lambda_{n} R^{*}\right), n=1,2, \ldots
$$

Values of $h^{*}\left(r^{*}, z^{*}\right)$ range from 0 to 1 .

\subsubsection{Fluxes and Stokes Stream Function $\psi^{*}\left(\mathrm{r}^{*}, \mathrm{z}^{*}\right)$}

One variable of primary interest is the transient drainage rate, $Q(t)$, which can be calculated using the dimensional parameters and variables in Equations (7) and (8):

$$
Q(t)=-2 \pi K_{z} \int_{0}^{R} \frac{\partial h(r, 0, t)}{\partial z} r d r=-2 \pi K_{r} L\left[H(t)-h_{w}\right] \cdot Q^{*}
$$

where the time-independent constant $Q^{*}$ was defined in Equation (9). Using Equations (18) and (19), one obtains:

$$
Q^{*}=Q^{*}\left(R^{*}, B i\right)=2 \sum_{n=1}^{\infty} \frac{\tanh \left(\lambda_{n}\right)}{\lambda_{n}\left[\left(\frac{\lambda_{n}}{B i}\right)^{2}+1\right]}
$$

The axial symmetry of the flow permits effective analysis of the kinematic flow structure inside the polygon using the time-independent Stokes stream function, $\psi^{*}\left(r^{*}, z^{*}\right)$. This function is related to $h^{*}\left(r^{*}, z^{*}\right)$ by conditions of orthogonality of their gradients:

$$
\frac{\partial \psi^{*}}{\partial r^{*}} \equiv-r^{*} \frac{\partial h^{*}}{\partial z^{*}}, \quad \frac{\partial \psi^{*}}{\partial z^{*}} \equiv r^{*} \frac{\partial h^{*}}{\partial r^{*}}
$$

subject to the condition:

$$
\psi^{*}(0,0)=0
$$

The latter equation indicates zero flux at the intersection of the polygon surface $(z=0)$ and the symmetry axis. Level curves of the function $\psi^{*}\left(r^{*}, z^{*}\right)$ are perpendicular to the equipotentials of head $h^{*}\left(r^{*}, z^{*}\right)$ for isotropic hydraulic conductivity conditions, which satisfies the Laplace equation at any moment in time. The flow net of streamlines and equipotentials provides a tool for visualizing the flow structure inside the thawed zone.

Using Equations (7), (8), (22), and (23), one obtains:

$$
\begin{aligned}
& \psi^{*}\left(r^{*}, z^{*}\right)=\int_{0}^{r^{*}} \frac{\partial h^{*}\left(r^{*}, z^{*}\right)}{\partial z^{*}} r^{*} d r^{*} \\
& =2 \sum_{n=1}^{\infty} \frac{J_{1}\left(\lambda_{n} r^{*}\right) r^{*}}{\lambda_{n} R^{*}\left[J_{0}\left(\lambda_{n} R^{*}\right)\left(\frac{\lambda_{n}}{B i}\right)+J_{1}\left(\lambda_{n} R^{*}\right)\right]} \frac{\sinh \left(\lambda_{n}(1-z)\right)}{\cosh \left(\lambda_{n}\right)}
\end{aligned}
$$

The maximal value of $\psi^{*}\left(r^{*}, z^{*}\right)$ is located at the point $z=0$ and $r=R$. The normalized dimensionless Stokes stream function varies between 0 and 1 :

$$
\Psi^{*}\left(r^{*}, z^{*}\right)=\frac{\psi^{*}\left(r^{*}, z^{*}\right)}{\max \left\{\psi^{*}\left(r^{*}, z^{*}\right)\right\}}=\frac{\psi^{*}\left(r^{*}, z^{*}\right)}{\psi^{*}\left(R^{*}, 0\right)}
$$


where

$$
\psi^{*}\left(R^{*}, 0\right)=Q^{*}
$$

Importantly, the positions of streamlines based on the dimensional and dimensionless normalized stream functions do not depend on time, but the flux magnitude does change over time, as defined in Equation (20).

\subsubsection{Center Pool Level H(t): Constant Thaw Depth}

The solution of the initial value problem (17) for depth $H^{*}\left(t^{*}\right)$ is:

$$
\frac{H(t)-h_{w}}{H_{0}-h_{w}}=H^{*}\left(t^{*}\right)=e^{-t^{*}}-E^{*}\left(1-e^{-t^{*}}\right), \quad t^{*}=\frac{t}{t_{L}}
$$

At large time values, this equation shows that the stabilized water level in the pool, $H_{\text {min }}$, is equal to or below the water level in the trough if $h_{w}$ remains constant:

$$
\underset{t \rightarrow \infty}{\lim H(t)}=H_{\min }=h_{w}-E \cdot t_{L}
$$

In the case of non-zero evaporation from the center pool, the drainage may become reversed, i.e., the trough with constant water level $h_{w}$ may become a source of water for the center pool.

The center pool will not be drained entirely, if

$$
H_{\min }=h_{w}-E \cdot t_{L}>L
$$

In other cases $H_{\min }$ can decrease to the elevation of the polygon surface and satisfy the condition $H\left(t_{\text {drain }}\right)=L$. In this case, the time of complete pool drainage continues from Equation (27) as follows:

$$
t_{\text {drain }}=t_{L} \ln \left(1+\frac{H_{0}-L}{L-h_{w}+E t_{L}}\right)
$$

\subsubsection{Center Pool Level H(t): Dynamic Thaw Depth, Analytical Approach}

In this case, $L(t)=D \cdot f(t)$, and the problem requires treatment of a moving bottom boundary, which requires additional effort. Equation (6) is amended by using the relationship in Equation (20):

$$
\pi R^{2} \frac{d H}{d t}=-2 \pi K_{r} L\left[H(t)-h_{w}\right] \cdot Q^{*}-\pi R^{2} E, \quad H(0)=H_{0}
$$

Which can be rewritten for integration considering the definitions of $t^{*}$ and $H^{*}$ in Equations (7) and (8) as follows:

$$
\frac{d H^{*}}{d t *}=-p\left(t^{*}\right) H^{*}-E^{*}, \quad H^{*}(0)=1
$$

The time-dependent coefficient $p\left(t^{*}\right)$ here is as follows:

$$
p\left(t^{*}\right)=\frac{2 K_{r}\left(H_{0}-h_{w}\right) f Q^{*}}{R^{2}}
$$

Which reflects a time-dependent, experimentally determined function $f$ for the active layer. Transient $f$ also creates time dependence in the parameters $R^{*}$ and $Q^{*}$ in Equation (9). Finally, integration of the linear Equation (32) is standard:

$$
H^{*}\left(t^{*}\right)=e^{-P\left(t^{*}\right)}-e^{-P\left(t^{*}\right)} \int_{0}^{t^{*}} e^{P(\eta)} E^{*}(\eta) d \eta, \quad P\left(t^{*}\right)=\int_{0}^{t^{*}} p(\xi) d \xi
$$




\subsubsection{Center Pool Level H(t): Dynamic Thaw Depth, Numerical Approach}

As an alternative to the methods described in Section 3.3.4, dynamic seasonally thawed zone thickness can also be accounted for by solving the model in a piecewise fashion, dividing the time domain into discrete timesteps. In this approach, the thawed zone thickness $L(t)$ is represented in table format and treated as forcing data for each timestep. Additionally, this approach permits head in the trough pool to likewise be defined in table format as a function of time, $h_{w}(t)$. An example using this approach to simulate the early-summer disappearance of a center pond near Utqiagvik, Alaska is presented in Section 4.3.

\subsection{Computation of Solutions}

Scripts for these calculations have been provided in the Supplementary Material. The methods used to investigate pool dynamics are determined by whether the thaw depth is treated as constant or dynamic.

When the thaw-layer thickness $L$ is steady, a constant value of $R^{*}$ is defined. Flow net calculations start with determining a set of $\lambda_{n}, n=1,2, \ldots$ in Equation (19). Convergence of the series in Equations (18) and (24) is generally rapid. Next, the dimensionless head is converted to dimensional format by Equation (11), and constant, dimensionless flux $Q^{*}$ is calculated using specific $R^{*}$ and $B i$ by Equation (21). This $Q^{*}$ is utilized in estimates of $t_{L}$ and pool depth dynamics, by Equations (10) or (27). Geometric and soil physical parameters are defined in the opening lines of the scripts and can easily be manipulated by the user. An example of this model is presented in Section 4.2.

When thaw-layer thickness $L$ is dynamic, the function $f$ must be known a priori in analytical or table format. The value of $R^{*}$ becomes time dependent according to Equation (33) because of the continuously changing polygon radius-to-depth ratio. Corresponding $\lambda_{n}, n=1,2, \ldots$ differ for each moment of time, together with $Q^{*}$ according to Equation (21). If the function $f$ is not provided as a continuous function, Equation (32) can be solved using a finite-difference approach on a discrete time grid, as described in Sections 3.5.2 and 4.3.

\subsection{Model Parameters for Demonstration}

\subsubsection{Constant Thaw-Layer Thickness}

To demonstrate the use of the model under assumptions of constant thaw-layer thickness, we used ranges for geometric and soil physical parameters of ice-wedge polygons derived from the literature. Based on ice-wedge polygon horizontal scale and vertical thickness from $[2,7,16,17]$, we explored aspect ratios $(R / L)$ ranging from 1 to 20 .

Our hydraulic conductivity values are derived from [18], who analyzed peat cores and determined heterogeneous $K_{r}$ in the range between 0.1 and $10 \mathrm{~m} /$ day, but typically on the order of $1 \mathrm{~m} /$ day. The anisotropy ratio $K_{r} / K_{z}$ had somewhat erratic behavior, often appearing nearly isotropic, but with a range extending from 0.1 and 10. Similar values for hydraulic conductivity were published by $[4,7,16,19,20]$, but these studies generally did not distinguish between $K_{r}$ and $K_{z}$. Estimates by [8] for high-centered and low-centered polygons had generally similar magnitudes of $K_{r}$.

Higher values of $K_{r}$ and $K_{z}$ are sometimes observed immediately in the top 0.2-0.3 m (relative to the underlying part of the active layer) by one or two orders of magnitude $[16,18]$. This scenario may effectively increase the initial effective pool depth and reduce the thickness of the active layer, but will not affect concepts of the model.

For characteristic cases, the maximum center pool depth in low-centered polygons, $H_{0}$, can be taken in the order of $0.5 \mathrm{~m}[2,5,15]$.

\subsubsection{Dynamic Thaw-Layer Thickness}

In order to validate the model in a scenario characterized by dynamic thaw-layer thickness, we calibrated it to match ponded water levels in a low-centered polygon during an early season 
drainage event in 2012 at the Barrow Environmental Observatory near Utqiagvik, Alaska (Area A in [5]). We used measured data from the site as boundary conditions for the model, including directly observed trough water levels. Meteorological forcing data consisted of observed precipitation from the Barrow, Alaska National Weather Service ground station and re-analyzed evapotranspiration from NASA's Global Land Data Assimilation System (GLDAS) [21]. Although the thaw depth was not measured directly in the polygon during the 2012 thaw season, it was measured directly during the 2013 and 2014 thaw seasons. Using the 2013 and 2014 thaw depth measurements and atmospheric conditions, we calibrated a permafrost heat flow model (Geophysical Institute Permafrost Laboratory (GIPL) model) [22] and simulated thaw depths for 2012 using air temperature and snow depth measured at the site. We applied these simulated thaw depths to control the dynamic thaw depth of the model.

In order to incorporate varying precipitation, evapotranspiration, trough water level, and thaw depth, we ran the model in piecewise fashion, restarting the model at each timestep with current boundary conditions. We included data from 6:00 AM, June 10 through 6:00 AM, July 2, 2012 (23 days) during which time the inundated low-centered polygon drained. The data was collected every $15 \mathrm{~min}$, resulting in 2112 timesteps in the analysis.

The adjustable parameters in the calibration were the horizontal and vertical hydraulic conductivity $\left(K_{r}\right.$ and $\left.K_{z}\right)$, the discharge conductance $(\kappa)$, and the initial ponded water level $(H(0))$. We calibrated the model using a Levenberg-Marquardt approach implemented in the Julia LsqFit package (https: //github.com/JuliaNLSolvers/LsqFit.j1). The objective function was the sum of the squared errors between the measured and simulated ponded water levels in the polygon center. Regularization terms were added to the objective function to penalize solutions where $K_{r}$ and $\kappa$ deviated from physical values. Assuming preferential horizontal (radial) flow, the value of $K_{z}$ was required to be less than $K_{r}$.

\section{Results}

\subsection{Flow Nets: Head and Flux Distributions}

To assess the effects of aspect ratio $R / L$ on flow dynamics, we assumed isotropic conditions $\left(K_{r}=K_{z}\right)$, and the coefficient $\kappa=2.0$ day $^{-1}$ (assuming $k$ as a fraction of $K_{r}$ (e.g., $\left.50 \%\right)$ and $l$ on the order of $0.25 \mathrm{~m}$ ). For a polygon $L=D=0.5 \mathrm{~m}$ thick, several horizontal polygon sizes were considered: $R=0.5,1.0,1.5,5.0$, and $10.0 \mathrm{~m}$.

The dimensionless parameters are as follows: $B i=\frac{\kappa L}{\sqrt{K_{r} K_{z}}}=\frac{2 \cdot 0.5}{\sqrt{1 \cdot 1}}=1$ and $R^{*}=\frac{R}{L} \sqrt{\frac{K_{z}}{K_{r}}}=$ $\frac{R}{0.5} \sqrt{1}=1,2,3,10$, and 20 (Figure 2). The latter two values correspond to commonly observed ice-wedge polygon radii of around 5-10 $\mathrm{m}$. For comparison, the smaller aspect ratios of $R^{*}=1,2$, and 3 are also shown, to highlight the impact of disparity between radial and vertical scales.

The shape of the flow net is steady during the drainage period, while the magnitude of each local velocity vector declines with the depth of water in the center pool, as defined in Equation (20). Considering that each stream tube conducts identical discharge toward the periphery of the polygon, the flux magnitudes near the polygon center and the trough differ by orders of magnitude.

These results indicate that the primary flux region is focused within about two vertical scales from the rim, when aspect ratio is approximately 3.0 or greater. This water flux disparity implies that advection-driven transport of solutes, heat, and soil particles may be concentrated near the periphery of an inundated polygon, while the center remains poorly flushed.

An investigation of model sensitivity to other contributing factors (hydraulic resistance of polygon-trough interface and anisotropy for commonly observed values) indicated that they are secondary to the effect of aspect ratio; these results are discussed in Appendix B. 

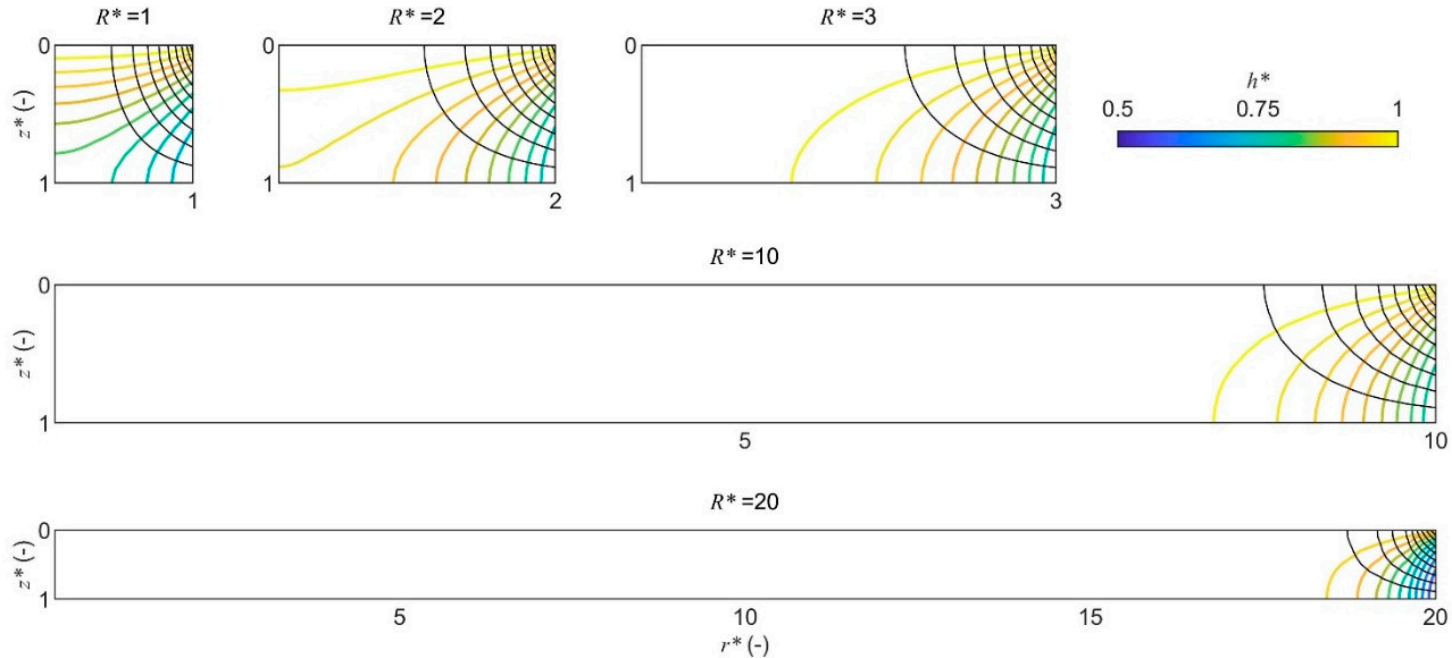

Figure 2. Effects of variable $R^{*}$ on the spatial distribution of fluxes across the polygon. The color bar applies to the head $h^{*}\left(r^{*}, z^{*}\right)$. All streamlines (in black) are contour lines of the stream function $\Psi^{*}\left(r^{*}, z^{*}\right)$, defining 10 stream tubes in total. The area (volume), conducting $90 \%$ of the water flux to the trough shifts toward the polygon edge with increasing $R^{*}$.

\subsection{Water Level Dynamics and the Role of Evapotranspiration}

The time scale $t_{L}$ is defined by Equation (9) through non-dimensional discharge $Q^{*}\left(R^{*}, B i\right)$. For simulations assuming a constant thaw-layer thickness $L$, we likewise assumed that the water level in the trough $h_{w}$ remains approximately constant during the time period of interest. Figure 3a indicates that discharge increases linearly with the anisotropy-adjusted aspect ratio, $R^{*}$, for practically any value of $B i$, the hydraulic conductance of the polygon drainage interface. This general graph can be utilized to evaluate of the polygon drainage dynamics, indicating that discharge is linearly dependent on the anisotropy-adjusted aspect ratio and is only dependent on the drainage interface when its conductance is significantly low.
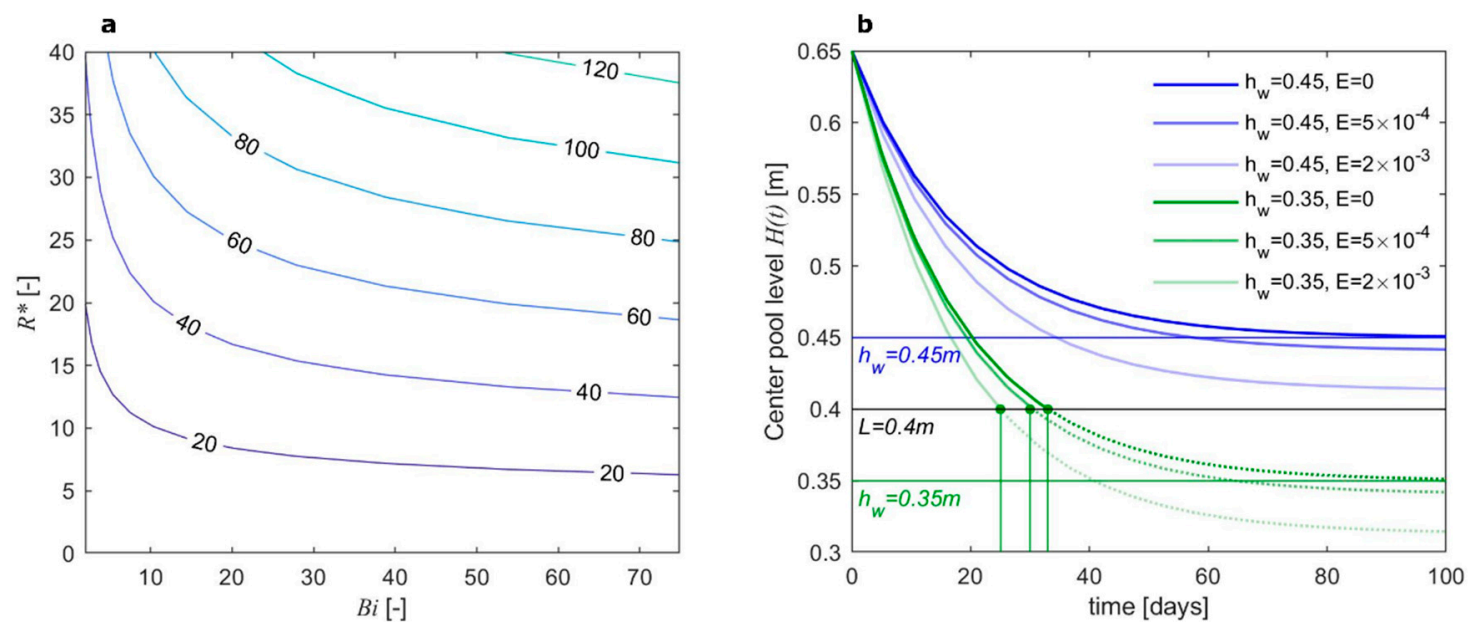

Figure 3. Drainage dynamics through the polygon: (a) dimensionless function $Q^{*}\left(R^{*}, B i^{*}\right)$, (b) example of center pool depth dynamics for specific parameter values with characteristic time scale $t_{L}=18$ days and different evaporation rates and water levels in the trough. Continuous lines show actual water level dynamics in the pool before complete draining; dashed lines are auxiliary and are mathematical, non-physical parts of the solution after drainage is complete. Times of draining $t_{\text {drain }}$ are indicated by stem plots on the time axis. 
For illustration, we considered drainage of a typical anisotropic polygon of radius $R=10 \mathrm{~m}$, thickness $L=0.4 \mathrm{~m}$, and rim-trough interface width $l \approx 0.5 \mathrm{~m}$. Conductive properties were as follows: $K_{r}=1 \mathrm{~m} /$ day, $K_{z}=0.2 \mathrm{~m} /$ day, and $k=0.5 \mathrm{~m} \mathrm{day}^{-1}$ (i.e., $\kappa=1.0$ day $^{-1}$ ). The initial center pool level was $H(0)=0.65 \mathrm{~m}$ (i.e., $0.25 \mathrm{~m}$ above the ground surface) and the water level in the trough was $h_{w}=0.45 \mathrm{~m}$. These parameters yielded dimensionless values $R^{*}=16.8$ and $B i=0.89$. The characteristic time of this problem was $t_{L}=18$ days. (Sensitivity of results to $\kappa$ is moderate at these values, as discussed in Appendix B).

Published experimental data on evapotranspiration $E$ in Siberia [4] and Alaska [7] using various field methods indicate typical values on the order of $10^{-3} \mathrm{~m} \mathrm{day}^{-1}$. Therefore, we used $E=0.5 \cdot 10^{-3} \mathrm{~m}$ day $^{-1}$ and $E=2 \cdot 10^{-3} \mathrm{~m} \mathrm{day}^{-1}$ to explore the effect on $t_{\text {drain }}$ values.

In Figure 3b, we show the dynamics of the pool water level following Equation (27). Here, water in the polygon center remains ponded indefinitely (Figure 3b), at the evaporation rates that we considered, because $H_{\text {min }}>L=0.4 \mathrm{~m}$ according to Equation (29).

The situation changes if the water level in the trough is at lower elevation than in the polygon center, e.g., if $h_{w}=0.35 \mathrm{~m}$. Equation (27) shows that the pool will drain entirely at any evaporation rate $\left(E=0,0.5 \cdot 10^{-3}\right.$, and $\left.2 \cdot 10^{-3} \mathrm{~m} \mathrm{day}^{-1}\right)$. Corresponding drainage times, calculated from Equation (30) are $t_{\text {drain }}=33,30$, and 25 days, and are similar to typical conditions observed in the Arctic, either at the start of the summer or following a large precipitation event in mid-summer $[5,8]$.

\subsection{Calibration of Center Pond Drainage Scenario with Dynamic Thaw-Layer Thickness at Utqiagvik}

Figure 4 presents the results of our calibration of the model against head data from the center pool in early summer at an inundated low-centered polygon near Utqiagvik, Alaska [5]. The simulation considered piecewise-linear gradual changes to the thickness of the thawed layer beneath the polygon center and observations of dynamic water level in the trough pool, as described in Sections 3.3.5 and 3.5.2. The final calibration demonstrates a very close match between observed and simulated head in the center pool, with a root mean squared error of $\sim 0.006 \mathrm{~m}$. Likewise, the calibrated parameters $K_{r}$, $K_{z}$, and $\kappa$ fit squarely within the ranges defined in Section 3.5.1, with an anisotropy ratio $K_{r} / K_{z}$ of $\sim 7.6$. The close match between observed and simulated head and the reasonable calibration of hydraulic parameters affirms the physical realism of our model in a scenario characterized by rapid changes in thaw-layer thickness and trough pool water level. A video illustrating these results is also available online in the Supplementary Material.

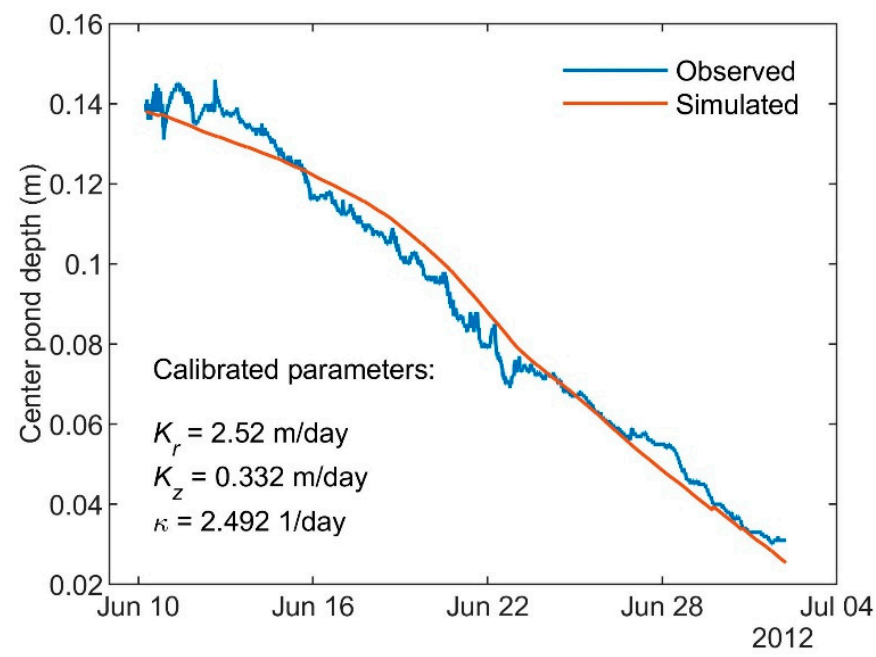

Figure 4. Observed and simulated center pool water level, from a piecewise-linear simulation of early summer drainage at a low-centered polygon near Utqiagvik, Alaska, accounting for temporal variability in thaw-layer thickness beneath the polygon center and water level in the trough pool. A video of this simulation is available online in the Supplementary Material. 


\section{Conclusions}

We developed a hydrodynamic model of inundated low-centered polygon drainage coupled with the center pool water balance and obtained an analytical solution. For conditions typically observed in polygonal tundra, a very strong edge effect was found; only a small fraction of the polygon located near the edges is flushed by the water drained from center pool storage. Confidence in the model is bolstered by the fact that simulated characteristic drainage time estimates are consistent with published observations, and the model accurately simulates the early summer disappearance of the center pond in a low-centered polygon when solved in a piecewise-linear fashion that accounts for dynamic thaw-layer thickness and water level in the trough pool. Some of the key insights derived from the model are:

1. Polygons are flushed most intensively at the edges for practically all existing physical and geometric parameters. The streamline patterns in this zone change little when the aspect ratio (radius-to-thickness of active layer) exceeds a value of three.

2. Anisotropy in hydraulic conductivity (horizontal-to-vertical hydraulic conductivity ratio) has a secondary influence on the intensity of flushing. Increases of anisotropy values counteract the effects of increased geometrical aspect ratio increases and vice versa (as discussed in Appendix B).

3. Hydraulic resistance of the drainage interface between the polygon and trough also has some limited, but not overriding influence within the typical range of Arctic tundra conditions.

4. Drainage time scales are consistent with observed duration of the center pool drainage within low-centered polygons. The parameter $t_{L}$ can be used to characterize drainage times from an inundated polygon center.

Supplementary Materials: The following are available online at http://www.mdpi.com/2073-4441/12/12/3376/ s1, File S1: Code for model execution, File S2: Video of simulated and observed center pond drainage at Utqiagvik, Alaska.

Author Contributions: V.A.Z. and D.R.H. conceived the concept for the study. V.A.Z. developed the analytical model, with context for the hydrological problem provided by D.R.H. and C.J.A., V.A.Z. wrote the original draft of the manuscript; edits and revisions were contributed by all authors. C.J.A. created figures to visualize the conceptual model and results. E.E.J. performed the calibration of the GIPL heat-flow model to 2013-2014 BEO, Site A polygon soil temperature measurements and provided simulated 2012 thaw depths. All authors have read and agreed to the published version of the manuscript.

Funding: The Next Generation Ecosystem Experiments Arctic (NGEE-Arctic) project (DOE ERKP757), funded by the Office of Biological and Environmental Research within the U.S. Department of Energy's Office of Science provided funding to D.R.H., C.J.A., and E.E.J. for this research.

Acknowledgments: We acknowledge discussions with K. Cole, UNL and thank him for providing a script to calculate eigenvalues.

Conflicts of Interest: The authors declare no conflict of interest.

\section{Appendix A. Derivation of the Head Distribution and Stokes Stream Function}

Using separation of variables for the boundary value problem in Equations (12)-(16) (e.g., [23]), one obtains:

$$
h^{*}\left(r^{*}, z^{*}\right)=\sum_{n=1}^{\infty} B_{n} \frac{\cosh \left(\lambda_{n} z\right)}{\cosh \left(\lambda_{n}\right)} J_{0}\left(\lambda_{n} r^{*}\right), \quad n=1,2, \ldots
$$

where $\lambda_{n}, n=1,2, \ldots$ are roots of the equation:

$$
\lambda_{n} J_{1}\left(\lambda_{n} R^{*}\right)=B i \cdot J_{0}\left(\lambda_{n} R^{*}\right), n=1,2, \ldots
$$


$J_{0}(\bullet)$ and $J_{1}(\bullet)$ are Bessel functions of the first kind, and coefficients $B_{n}$ are as follows:

$$
B_{n}=\frac{\int_{0}^{R^{*}} J_{0}\left(\lambda_{n} r^{*}\right) r^{*} d r^{*}}{\int_{0}^{R^{*}} J_{0}^{2}\left(\lambda_{n} r^{*}\right) r^{*} d r^{*}}
$$

Estimation of $B_{n}$ uses identities:

$$
\int_{0}^{z} t^{v} J_{v-1}(t) d t=z^{v} J_{v}(z), v=1, \int_{0}^{z} t J_{0}^{2}(t) d t=\frac{z^{2}}{2}\left[J_{0}^{2}(z)+J_{1}^{2}(z)\right]
$$

(See [24], Equations (11.3.20) and (11.3.34)) and their special cases:

$$
\begin{gathered}
\int_{0}^{R^{*}} J_{0}\left(\lambda_{n} r^{*}\right) r^{*} d r^{*}=\frac{R^{*} J_{1}\left(\lambda_{n} R^{*}\right)}{\lambda_{n}} \\
\int_{0}^{R^{*}} J_{0}^{2}\left(\lambda_{n} r^{*}\right) r^{*} d r^{*}=\frac{R^{* 2}}{2}\left[\begin{array}{l}
2 \\
0
\end{array} \frac{2}{2}\left(\lambda_{n} R^{*}\right)+J_{1}^{2}\left(\lambda_{n} R^{*}\right)\right]
\end{gathered}
$$

These identities fully determine coefficients $B_{n}$, resulting in Equation (18).

\section{Appendix B. Role of Hydraulic Resistance of the Polygon-trough Interface and Anisotropy}

The parameter $\mathrm{Bi}$ accounts for hydraulic resistance of the interface between the polygon and trough (see Equation (7)). High values indicate that the head in the polygon at the periphery of the polygon center is near-equal to the head inside the trough. To estimate the effect of this parameter, in Figure A1, we display streamlines near the rim of a polygon with dimensionless radius $R^{*}=10$, within range of radii $r^{*}$ between 8.5 and 10 (radii between 0 and 8.5 are omitted). Selected values of $B i$ $(0.01,1.0$, and 10$)$ reflect limited data available for polygonal soils.

Stream function near the trough for $B i=0.01,1$, and 10

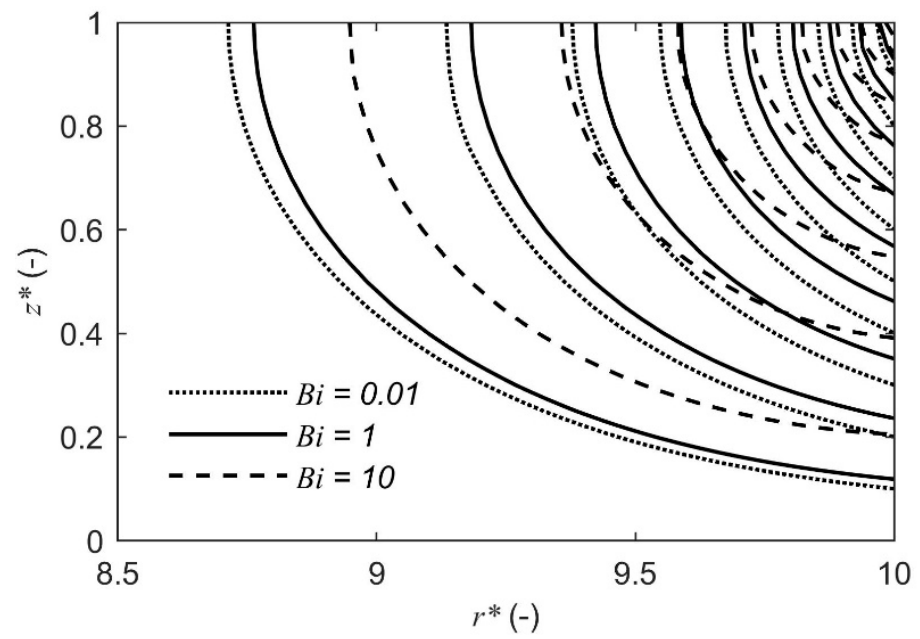

Figure A1. Three sets of streamlines corresponding to values of $B i=0.01,1.0$, and 10. Each stream tube carries $10 \%$ of the flux, so the area (volume) above the lower streamline in each set contains $90 \%$ of the water flux.

A comparison of streamlines indicates that the ten-fold increase in $B i$ from 1 to 10 has more effect than the hundred-fold increase in $B i$ from 0.01 to 1 . A reduction in hydraulic resistance also leads to vertical and radial "shrinking" of the streamlines for $B i=10$. This phenomenon can be interpreted as follows: a better hydraulic connection intensifies flushing near the top and the outer edges of the 
active layer in the polygon center. Although the effect is modest, this comparison contextualizes the importance of accurately defining hydraulic properties in the polygon rim.

The effect of anisotropy in hydraulic conductivity $K_{r} / K_{z}$ is to alter both the parameters $R^{*}$ and $B i$, as indicated in Equation (7). However, a somewhat limited effect of $B i$ on the kinematic structure of flow in the polygon generally indicates that anisotropy has moderate influence on the edge effect. For example, $K_{r} / K_{z}=4$ would reduce the value of $R^{*}$ by a factor of two, which would be equivalent to a reduction in $R^{*}$ from 20 to 10 in Figure 2 in the main text. This indicates that an increase in the anisotropy can redistribute the flux over the polygon, thereby reducing the edge effect.

\section{References}

1. Jorgenson, M.T.; Shur, Y.L.; Pullman, E.R. Abrupt increase in permafrost degradation in Arctic Alaska. Geophys. Res. Lett. 2006, 33, L024960. [CrossRef]

2. Liljedahl, A.; Boike, J.; Daanen, R.; Fedorov, A.N.; Frost, G.V.; Grosse, G.; Hinzman, L.D.; Iijma, Y.; Jorgenson, J.C.; Matveyeva, N.; et al. Pan-Arctic ice-wedge degradation in warming permafrost and its influence on tundra hydrology. Nat. Geosci. 2016, 9, 312-318. [CrossRef]

3. Farquharson, L.M.; Romanovsky, V.E.; Cable, W.L.; Walker, D.A.; Kokelj, S.V.; Nicolsky, D. Climate change drives widespread and rapid thermokarst development in very cold permafrost in the Canadian High Arctic. Geophys. Res. Lett. 2019, 46, 6681-6689. [CrossRef]

4. Helbig, M.; Boike, J.; Langer, M.; Schreiber, P.; Runkle, B.R.; Kutzbach, L. Spatial and seasonal variability of polygonal tundra water balance: Lena River Delta, northern Siberia (Russia). Hydrogeol. J. 2013, 21, 133-147. [CrossRef]

5. Liljedahl, A.K.; Wilson, C.J. Ground Water Levels for NGEE Areas A, B, C, and D, Barrow, Alaska, 2012-2014; Next Generation Ecosystems Arctic Data Collection; Oak Ridge National Laboratory, U.S. Department of Energy: Oak Ridge, TN, USA, 2016. [CrossRef]

6. Koch, J.C.; Gurney, K.; Wipfli, M.S. Morphology-dependent water budgets and nutrient fluxes in Arctic thaw ponds. Permafr. Periglac. Process. 2014, 25, 79-93. [CrossRef]

7. Koch, J.C.; Jorgenson, M.T.; Wickland, K.P.; Kanevskiy, M.; Striegl, R. Ice wedge degradation and stabilization impact water budgets and nutrient cycling in Arctic trough ponds. J. Geophys. Res. Biogeosci. 2018, 123, 2604-2616. [CrossRef]

8. Wales, N.A.; Gomez-Velez, J.D.; Newman, B.D.; Wilson, C.J.; Dafflon, B.; Kneafsey, T.J;; Wullschleger, S.D. Understanding the relative importance of vertical and horizontal flow in ice-wedge polygons. Hydrol. Earth Syst. Sci. 2020, 24, 1109-1129. [CrossRef]

9. Cory, R.M.; Ward, C.P.; Crump, B.C.; Kling, G.W. Sunlight controls water column processing of carbon in arctic fresh waters. Science 2014, 345, 925-928. [CrossRef] [PubMed]

10. Jan, A.; Coon, E.T.; Painter, S.L.; Garimella, R.; Moulton, J.D. An intermediate-scale model for thermal hydrology in low-relief permafrost-affected landscapes. Comput. Geosci. 2018, 22, 163-177. [CrossRef]

11. Aas, K.S.; Martin, L.; Nitzbon, J.; Langer, M.; Boike, J.; Lee, H.; Berntsen, T.K.; Westermann, S. Thaw processes in ice-rich permafrost landscapes represented with laterally coupled tiles in a land surface model. Cryosphere 2019, 13, 591-609. [CrossRef]

12. Nitzbon, J.; Langer, M.; Westermann, S.; Martin, L.; Aas, K.S.; Boike, J. Pathways of ice-wedge degradation in polygonal tundra under different hydrological conditions. Cryosphere 2019, 13, 1089-1123. [CrossRef]

13. Nitzbon, J.; Westermann, S.; Langer, M.; Martin, L.C.; Strauss, J.; Laboor, S.; Boike, J. Fast response of cold ice-rich permafrost in northeast Siberia to a warming climate. Nat. Commun. 2020, 11, 2201. [CrossRef]

14. Dobinksi, W. Permafrost active layer. Earth Sci. Rev. 2020, 208, 103301.

15. Abolt, C.J.; Young, M.H. High-resolution mapping of spatial heterogeneity in ice wedge polygon geomorphology near Prudhoe Bay, Alaska. Sci. Data 2020, 7, 87. [CrossRef] [PubMed]

16. Quinton, W.L.; Hayashi, M.; Carey, S.K. Peat hydraulic conductivity in cold regions and its relation to pore size and geometry. Hydrol. Process. 2008, 22, 2829-2837. [CrossRef]

17. Abolt, C.J.; Young, M.H.; Caldwell, T.G. Numerical modelling of ice-wedge polygon geomorphic transition. Permafr. Periglac. Process. 2017, 28, 347-355. [CrossRef]

18. Beckwith, C.W.; Baird, A.; Heathwaite, A.L. Anisotropy and depth-related heterogeneity of hydraulic conductivity in a bog peat. I: Laboratory measurements. Hydrol. Process. 2003, 17, 89-101. [CrossRef] 
19. Chason, D.B.; Siegel, D.I. Hydraulic conductivity and related physical properties of peat, Lost River Peatland, Northern Minnesota. Soil Sci. 1986, 142, 91-99. [CrossRef]

20. Ebel, B.A.; Koch, J.C.; Walvoord, M.A. Soil physical, hydraulic, and thermal properties in interior Alaska, USA: Implications for hydrologic response to thawing permafrost conditions. Water Resour. Res. 2019, 55, 4427-4447. [CrossRef]

21. Rodell, M.; Houser, P.R.; Jambor, U.; Gottschalck, J.; Mitchell, K.; Meng, C.-J.; Arsenault, K.; Cosgrove, B.; Radakovich, J.; Entin, M.B.J.K.; et al. The Global Land Data Assimilation System. Bull. Am. Meteorol. Soc. 2004, 85, 381-394. [CrossRef]

22. Jafarov, E.E.; Marchenko, S.S.; Romanovsky, V.E. Numerical modeling of permafrost dynamics in Alaska using a high spatial resolution dataset. Cryosphere 2012, 6, 613-624. [CrossRef]

23. Mackowski, D.W. Conduction Heat Transfer, Notes for MECH 7210. Mechanical Engineering Dept., Auburn University, 2020. Available online: http://www.eng.auburn.edu/ \{\}dmckwski/mech7210/condbook.pdf (accessed on 24 September 2020).

24. Abramowitz, M.; Stegun, I. Handbook of Mathematical Functions: With Formulas, Graphs, and Mathematical Tables; Dover Publications: Mineola, NY, USA, 1965.

Publisher's Note: MDPI stays neutral with regard to jurisdictional claims in published maps and institutional affiliations.

(C) 2020 by the authors. Licensee MDPI, Basel, Switzerland. This article is an open access article distributed under the terms and conditions of the Creative Commons Attribution (CC BY) license (http://creativecommons.org/licenses/by/4.0/). 